\title{
Como ser Pós-Humano na Rede: os Discursos da Transcendência nos Manifestos Ciberculturais ${ }^{1}$
}

\author{
Erick Felinto 2 \\ Universidade do Estado do Rio de Janeiro \\ erickfo@ajato.com.br \\ Mauro Schulz de Carvalho 3 \\ Universidade do Estado do Rio de Janeiro \\ mschulz_c@yahoo.com.br
}

\begin{abstract}
Resumo: Este trabalho visa analisar a retórica dos manifestos dos movimentos e associações pós-humanistas disponíveis na Internet. Parte-se da hipótese de que os discursos da exaltação do desenvolvimento tecnológico fundamentam-se em um imaginário essencialmente religioso, que tem como base a defesa da transcendência humana por meio da tecnociência. Tais discursos revelam-se, ao cabo de cuidadosa análise, como expressões ingênuas de uma imaginação utópica carente de vetores críticos quanto a suas concepções sobre o fenômeno tecnológico.

Abstract: This article aims to analyze the rhetoric characteristic of many post humanists' manifestos available on the internet. We hypothesize that these discourses of technological exaltation rest on the idea of human transcendence by means of contemporary technoscience. A careful analysis discloses these discourses as naïve expressions of an utopist imagination that lacks critical assessments regarding its conceptions about the technological phenomenon..
\end{abstract}

Palavras-chave: Cibercultura; Transcendência; Imaginário Tecnológico; Manifestos; Pós-Humanismo

Keywords: Cyberculture; transcendence; technological imaginary; manifestos; post humanism.

\footnotetext{
${ }^{1}$ Trabalho apresentado ao NP 02 - Tecnologias da Informação e da Comunicação, do IV Encontro dos Núcleos de Pesquisa da Intercom.

2 Professor Adjunto, Coordenador do Mestrado em Comunicação Social- UERJ.

3 Estudante de graduação, Bolsista de Iniciação Científica no Projeto "Crítica do Imaginário Tecnológico: Novas Tecnologias e Imagens da Transcendência”.
} 
$\mathrm{O}$ advento das tecnologias digitais acarretou significativas transformações não apenas nas estruturas e formas do processo comunicacional, mas também nos modos como as sociedades imaginam e representam suas experiências tecnológicas. Se, de fato, é possível falar de algo como um "imaginário tecnológico" - expressão utilizada, com sentido equivalente, por autores tão diversos como Rüdiger (2002), Sfez (1996) ou Ferrer (1996), entre outros - não deve surpreender que nossas concepções sobre a comunicação e os procedimentos de mediação tecnológica venham alterando-se significativamente nos últimos anos.

Contudo, não obstante todo o interesse que as mudanças tecnológicas têm despertado entre os pesquisadores da área, muito "pouca atenção têm sido devotada às possíveis alterações na concepção da tecnologia" - como bem adverte L.R.Rutsky (1999: 2). O imaginário tecnológico, conjunto de idéias, representações, conceitos ou mitemas ${ }^{4}$ a respeito das tecnologias (especialmente, claro, as tecnologias de comunicação, as mais diretamente presentes no cotidiano dos sujeitos contemporâneos), ainda é uma espécie de no man's land, território vago e indefinido no mapa epistemológico de nossos estudos culturais e comunicacionais. Essa carência de pesquisas sobre as representações culturais do tecnológico não deixa de surpreender quando nos damos conta de que nosso uso das tecnologias é fortemente condicionado pelas concepções que delas fazemos.

Para sermos inteiramente justos, porém, é preciso reconhecer que, pelo menos no campo específico dos estudos de cibercultura, alguns autores já têm se aventurado em pesquisas dedicadas a analisar as representações tecnológicas. Entre os exemplos mais significativos, podemos citar Coyne (2001), Breton (2000), Davis (1998) e Lemos (2002). O presente artigo almeja precisamente alinhar-se com os esforços desses estudiosos. Ele é fruto do trabalho possibilitado por uma bolsa de iniciação científica concedida pela

4 O termo, cunhado por Lévy Strauss, é utilizado por Jeffrey Sconce em Haunted Media (2000: 10). 
UERJ ao projeto "Crítica do Imaginário Tecnológico: Novas Tecnologias e Imagens da Transcendência”, cujo objetivo era investigar a manifestação de determinados aspectos do imaginário tecnológico contemporâneo na própria Internet. Mais precisamente, estávamos interessados em estudar os websites de alguns movimentos e associações nos quais fosse possível identificar um conjunto de representações sobre as tecnologias contemporâneas em suas relações com uma visão de mundo que poderíamos denominar como "cibercultural".

Já se disse que a cibercultura consiste, na verdade, em uma série de subculturas, com suas próprias particularidades, mas que compartilham determinados ideais, estilos de vida e visões de mundo (Cf. Terranova, 2002). Para os efeitos de nosso estudo, interessavam especificamente as subculturas centradas em torno do tema do pós-humanismo. Tratava-se de verificar de que modo entidades como a World Transhumanist Association (WTA) ou o Extropy Institute (EI) representam o tema das relações entre a humanidade e as tecnologias contemporâneas. Mais especificamente ainda, o estudo procuraria identificar, no âmbito dos discursos que circulam pela rede em páginas de instituições e movimentos como os acima mencionados, uma peculiar concepção do fenômeno tecnológico, centrada na idéia de um poder quase mágico ou religioso da tecnologia como instrumento para a transcendência humana.

Nos estudos sobre a cibercultura, o tema do pós- ou transhumanismo vem ocupando posição cada vez mais destacada, articulando-se com uma diversidade de outros importantes temas, como os do ciborgue (Cf. Haraway, 2000) ou o do abandono do corpo físico por meio das tecnologias digitais (Cf. Le Breton, 1999). Como afirma Tiziana Terranova, a questão do póshumanismo "não é apenas mais uma das excessivas manifestações do espírito cibercultural, mas também uma útil via de entrada no discurso cibercultural como um todo" (2002: 276). O pós-humano é precisamente aquele ser ou 
indivíduo que faz pleno uso do imenso potencial das "novas tecnologias" a seu dispor. Ele é o explorador por excelência dos novos territórios da cibercultura, criatura da conectividade, navegador do ciberespaço, híbrido artificial-orgânico capaz de abrir mão das certezas da condição humana em benefício das ainda incertas aventuras proporcionadas pela prazerosa "confusão de fronteiras" (Haraway, 2000: 42). Nesse sentido, ele parece constituir um vértice em torno do qual transitam as principais imagens, símbolos e representações do mundo cibercultural.

As tonalidades religiosas das narrativas sobre o pós-humano já foram denunciadas por diversos estudiosos do tema. Contudo, ainda são poucos os estudos que se aprofundam no detalhamento desse peculiar imaginário em sua apropriação de noções características do discurso religioso. Este artigo visa, portanto, evidenciar e descrever os pontos de articulação entre póshumanismo e religiosidade tecnológica nos discursos apresentados em um conjunto de oito sites investigados no decorrer da pesquisa. É importante advertir que a presença de imagens religiosas ou espiritualistas não constitui exatamente uma novidade relativa unicamente aos discursos sobre as novas tecnologias. O interesse de estudos como Haunted Media, de Jeffrey Sconce, radica-se, de fato, na demonstração de que essa peculiar associação entre tecnologias (especialmente as comunicacionais) e espiritualidade pode ser traçada desde a invenção do telégrafo ou mesmo antes. Em um cuidadoso estudo de crítica cultural, Sconce identifica a penetração de tais mitologias também nas representações populares sobre o rádio, a televisão e a Internet. Como explica o autor, "sonhos de um completo abandono do corpo e penetração em um plano de existência mais rarefeito deslocaram-se definitivamente da metafísica da igreja para aquela dos chips de computador" (Sconce, 2000: 19-20).

Passeando por artigos publicados em revistas como a TV Guide, programas de televisão, filmes e mesmo textos teóricos, Sconce nos apresenta 
um imaginário cultural onde as tecnologias eletrônicas e digitais são representadas como possíveis portais para uma outra dimensão da experiência. Nessa dimensão imaterial, o sujeito pode desvincular-se do corpo alcançando um estado de transcendência em que suas faculdades são ampliadas e onde as fronteiras entre o espiritual e o material são franqueadas. Por mais obscuras e exóticas que essas conexões possam parecer, uma rápida busca no Google basta para revelar diversas pérolas desse imaginário "tecnoespiritual”. Em uma reportagem apresentada no periódico online The Sacramento Bee, por exemplo, lemos sobre a experiência do marceneiro alemão Manfred Boden, assombrado pelo espírito de um recém-falecido amigo em seu terminal de computador. A matéria narra a surpresa do pobre marceneiro, ao ver sua máquina adquirir vida própria e escrever, sozinha, na tela a mensagem: "Manfred, estou aqui... seu amigo Klaus"5.

Mas se essa imaginação tecno-espiritual acompanha as tecnologias comunicacionais (e mesmo, poder-se-ia dizer, o fenômeno tecnológico lato sensu, como sugere David Noble, 1999) há longo tempo, em que sentido seria possível apontar a especificidade do imaginário tecnológico contemporâneo? É precisamente essa nova articulação que nos interessa. Uma articulação evidenciada pelo tema do pós-humanismo. Se em imaginários anteriores as tecnologias eram representadas eminentemente como instrumentos de "transporte" externos ao sujeito ou portais para uma dimensão metafísica, no âmbito das mitologias digitais elas passam a ser imaginadas como partes integrantes da própria subjetividade.

Segundo Sconce, é possível traçar uma importante distinção na passagem de tecnologias como o telégrafo e o rádio para a televisão. As primeiras eram figuradas freqüentemente como passagens abertas entre o mundo material e uma outra dimensão metafísica da existência. Em função

5 Cf. Hoyle, David. "Ghosts Making Contact via Computer? Stories Abound”, disponível online em http://www.sacbee.com/content/business/v-print/story/5011823p6019855c.html. 
de suas características técnicas, como a ilusão da criação realidades sonoras e visuais autônomas, a televisão "veio a ser concebida não apenas como uma extensão eletrônica da visão humana, mas como um misterioso espaço eletrônico em si mesmo" (Sconce, 2000: 17). No novo mundo das tecnologias digitais, podemos apontar ainda uma outra transição importante: agora já não é possível sequer delimitar qualquer distância entre o sujeito e as tecnologias que o modificam continuamente. Numa expansão crescente do território midiático-imaginal aberto pela televisão, as tecnologias da simulação passam a engendrar uma "identidade terminal” (Bukattman, 1998), um sujeito híbrido cuja consciência se dissolve por completo no infindável território virtual das redes de computadores. E esse sujeito já não é mais tanto vítima de um processo de dissolução do real que o oprime quanto o protagonista ou mesmo demiurgo dos novos e melhores mundos virtuais ${ }^{6}$.

\title{
O que é o Pós-Humanismo? Considerações Iniciais
}

O site "posthuman.com" oferece uma definição inicial que soa como objetiva e direta, ao mesmo tempo em que revela ingenuidade e imprecisão perturbadoras. A página, apenas um portal com links para os principais sites ligados ao tema, assim descreve o conceito:

\begin{abstract}
um ser consciente que se iniciou como um humano ou uma mente com modo de pensar humano - e, em seguida, através da utilização de tecnologias, converte-se em alguém que não é mais humano. Tais seres pós-humanos não existem atualmente, de modo que qualquer definição mais detalhada de como eles se pareceriam, pensariam ou comportar-se-iam não passa de pura especulação (http://www.posthuman.com/).
\end{abstract}

\footnotetext{
${ }^{6}$ Naturalmente, o imaginário distópico também faz parte de certas vertentes dos discursos ciberculturais. É o que se passa, por exemplo, no campo da ficção ciberpunk. Contudo, o imaginário que cercava a introdução das tecnologias televisivas era muito mais nitidamente apocalíptico e sombrio. Hoje parece seguro afirmar que a tendência mais marcada do imaginário tecnológico contemporâneo é a utopia. Em muitos discursos desse imaginário, o sujeito aparece como ser dotado de incrível poder de manipular e reformar a realidade. $\mathrm{O}$ infonauta é o pós-humano criador de um mundo melhor, mais perfeito e mais eficiente, pois nenhum de seus elementos é abandonado ao acaso. Tornar-se pós-humano significa não apenas estar no comando de seu destino, mas também da própria realidade que o cerca.
} 
Não se oferece mais nenhum detalhe a respeito do que significa ser humano ou de que modo as tecnologias condicionariam a conversão do sujeito para o âmbito da pós-humanidade. É certo, porém, que a definição não se coaduna com uma das expressões mais célebres da mitologia pós-humanista, o ciborgue de Donna Haraway. Para Haraway, na qualidade de criaturas que continuamente fazem uso de técnicas e artifícios, já somos todos ciborgues, "híbridos - teóricos e fabricados - de máquina e organismo" (2000: 41). Não obstante diversas outras proximidades com as formulações teóricas do "Manifesto Ciborgue" 7, as subculturas aqui investigadas encaram a condição pós-humana mais como potencialidade futura do que como realidade corrente. Haraway interessa-se especialmente pela figura do ciborgue como uma metáfora política de nossa condição contemporânea, como uma figura interessante para pensar o presente. Nesse sentido, o breve fragmento não é apenas divertido em sua ingenuidade, mas serve para alertar-nos quanto a dois importantes aspectos dos discursos pós-humanistas.

Em primeiro lugar, a retórica de tais discursos é caracteristicamente projetiva. Em outras palavras, o pós-humano é sempre projetado num futuro ainda a cumprir-se, o que aproxima os manifestos pós-humanistas da estrutura dos textos da ficção científica. A "Declaração Transhumanista" se inicia com a afirmação de que "a humanidade será radicalmente alterada pela tecnologia no futuro"8. A maior parte dos verbos aparece no futuro ou indicam futuridade (foresee, coming developments, prospect, etc), de modo a permitir um vasto campo de possibilidades imaginárias para os desenvolvimentos das sociedades tecnológicas. Como bem afirma Richard

\footnotetext{
7 Por exemplo, a idéia de que todos os seres, independentemente de seu estatuto ontológico (animais, seres artificiais, etc), merecem o mesmo respeito devotado aos humanos.

8 Todos os trechos da "Declaração Transhumanista" foram extraídos de http://transhumanist.org/index.php/WTA/declaration. É importante lembrar que essa "retórica da futuridade" não é um traço apenas dos discursos pós-humanistas, mas do imaginário cibercultural como um todo.
} 
Coyne, "as narrativas digitais são sempre expectantes (...) enfatizam o que será realizado, minimizando as conquistas presentes, que são inevitavelmente mais modestas que as predições" (2001: 19). Tais discursos não estão tão interessados nas realidades concretas do presente quanto nas virtualidades abertas de um hipotético (ou fictício) porvir.

O segundo aspecto é o caráter de imprecisão das definições e conceitos defendidos nos discursos pós-humanistas. No setor das questões mais perguntadas do site do Extropy Institute, podemos ler a seguinte definição de "transhumano": "somos transhumanos na medida que buscamos nos tornar pós-humanos e tomar iniciativas para nos prepararmos para um futuro póshumano” (apud Terranova, 2002: 273). A retórica projetiva é apresentada em uma frase quase risível por seu caráter tautológico. Essa combinação entre potencialidade futura e imprecisão conceitual só faz ampliar nossa sensação de transitar em um território eminentemente ficcional ou mítico. Dessa forma, não deve surpreender que a indefinição também se manifeste em formas discursivas que têm no recurso à metáfora um de seus principais instrumentos. Essa proliferação da metáfora é um traço genérico da discursividade cibercultural, como apontam diversos autores. Ela aponta para uma forma mentis analógica, comparativa, pouco consciente de seu próprio estatuto. “A Extropia é uma metáfora que se refere a atitudes e valores compartilhados por aqueles que desejam ultrapassar os limites humanos por meio da tecnologia”, esclarece o Tranhumanist FAQ do site do Instituto Extropiano (http://www.extropy.org/faq.htm, grifos nossos).

\section{Transcendência e Espiritualidade Tecnológica}

A idéia da ultrapassagem dos limites humanos expressa na frase acima nos dá oportunidade de iniciar a discussão sobre o que parece ser a principal característica dos discursos pós-humanistas presentes nos sites objetos da presente pesquisa: a repetição exaustiva do tema da transcendência. Não 
existe limitação ou estado que não possa (e deva) ser superado, o importante é a expansão permanente, o aperfeiçoamento interminável de todas as faculdades humanas. A própria lógica do manifesto ou declaração (the Cyborg Manifesto, the Hacktivismo Declaration, the Viridian Manifesto, etc...) aponta para essa curiosa comunhão entre as narrativas ciberculturais e as propostas das vanguardas estéticas dos princípios do século XX. A infindável sucessão de movimentos, manifestos e declarações de princípios era sintomática da necessidade de renovação constante, da ultrapassagem de todos os vínculos com as tradições passadas, das rupturas e revoluções permanentes. É de fato uma lógica que implica continuamente um futuro sempre possível, mas nunca inteiramente cumprido. O "Manifesto Viridiano" constitui um excelente exemplo dessa estratégia discursiva:

O milênio que se aproxima rapidamente oferece uma oportunidade cultural única. Após muitos anos de corte e colagem (cut-and-paste), apropriação, desvio e anhistoricidade neo-retrô, a pós-modernidade está prestes a acabar. Imediatamente após o fim do fin de siècle haverá uma repentina e intensa demanda por novidades genuínas (http://www.viridiandesign.org/manifesto.html)

Para R.L. Rutsky não é nenhuma coincidência que a retórica exagerada dos discursos sobre as novas tecnologias lembre os manifestos e slogans das vanguardas, já que elas envolvem também um imaginário de beleza e perfeição estética: "O High Tech é, de fato, freqüentemente apresentado como uma espécie de movimento de vanguarda"9 (1999: 5) Essa necessidade de permanente superação está também na base dos discursos da transcendência na rede. Transcender e tornar-se pós-humano significa romper continuamente as fronteiras que tradicionalmente caracterizavam nossa condição, inclusive a própria idéia de mortalidade. Prefixos como "pós" e “trans” já são indicativos do desejo de superar todo e qualquer estado

\footnotetext{
9 Rutsky denomina as tecnologias eletrônicas e digitais como High Tech, caracterizando-as, precisamente, como tecnologias nas quais o estilo, a visualidade, a elegância das formas, em suma, a aparência, é muitas vezes mais importante que sua própria funcionalidade.
} 
presente, seja ele de natureza social, espiritual ou biológica. Como explica o FAQ do Instituto Extropiano, citando as palavras de seu presidente Max More, a filosofia do transhumanismo enquadra-se em um conjunto de "Filosofias da vida, tais como a extropia, que buscam a continuação e aceleração da evolução da vida inteligente para além de sua forma corrente e de suas limitações humanas por meio de ciência e da tecnologia guiadas por princípios e valores promotores da vida" (http://www.extropy.org/faq.htm\#2.1).

Curiosamente, a retórica de alguns desses movimentos defende a idéia de que o pós-humano é, na verdade, mais humano do que os humanos comuns. Transcender significaria, em realidade, alcançar uma condição à qual o homem é destinado em sua essência. De fato, o site da World Transhumanist Association afirma explicitamente que o movimento pode ser encarado como uma "extensão" do humanismo. No item que discute o conceito de pós-humano fica claro, porém, que as potencialidades desse processo ainda estão muito longe de realizar-se. Ser um transhumanista significa defender, de fato, uma certa filosofia de vida, mas não implica que o sujeito seja efetivamente pós-humano. Por vezes, parece estabelecer-se uma distinção entre o pós-humano como possibilidade futura e o transhumano como um ser transicional, alguém que representa o momento intermediário da passagem entre a humanidade e essa super-humanidade do porvir (Cf. http://transhumanism.org/index.php/WTA/faq21/57/). Ele seria talvez um equivalente do conceito de homem pneumático das seitas gnósticas dos primeiros séculos. O homem pneumático é aquele que tem as capacidades e disposições espirituais adequadas para o retorno ao estado de bemaventurança no paraíso originário ${ }^{10}$.

\footnotetext{
${ }^{10}$ Acreditamos firmemente na possibilidade de encarar a religiosidade tecnológica do póshumanismo como um análogo da forma mentis característica das antigas gnoses e hermetismos. Essa aproximação não é exatamente algo inusitado, já tendo sido sugerida por diversos estudiosos, como Breton, Le Breton, Martins, Sibilia e Davis, entre outros. Sobre a figura do homem pneumático e suas ligações com a popular metáfora do anjo ciberespacial, ver artigo de Erick Felinto "Techno-Religion and the Pneumatic Subject in Ciberculture's Imaginary", a ser publicado no próximo volume da Agenda of the Millenium, Unesco/Ucam.
} 
Não se pode negar que a associação dessas subculturas com o tema religioso é complexa e ambígua. Mas também não se pode duvidar de que os discursos da transcendência sugerem pelo menos algumas vias de conexão com o universo da retórica espiritualista. Como afirma Mark Dery, a cibercultura

\begin{abstract}
Ressoa com fantasias transcendentalistas de romper com os limites de todos os tipos, tanto físicos como metafísicos. Ironicamente, a mesma visão de mundo científica e a incessante aceleração tecnológica às quais muitos atribuem o vácuo espiritual e a fragmentação social que são férteis solos para crenças milenaristas estão engendrando uma tecno-escatologia própria - uma teologia do assento ejetor (1996: 8).
\end{abstract}

É verdade que movimentos como a WTA e o Viridian Design recusam qualquer associação explícita com o campo religioso (mas não faltam outros, como veremos, que defendem essas conexões claramente). Contudo, a retórica de seus discursos e muitos de seus temas apresentam estruturas características dos discursos da religião. A longa, mas importante, passagem abaixo, extraída do FAQ do WTA basta para demonstrar essa associação (senão de conteúdo, pelo menos em termos de forma):

Apesar de não ser uma religião, o transhumanismo pode servir a algumas das mesmas funções que as pessoas tradicionalmente procuraram na religião. Ele oferece um sentido de direção e propósito e sugere uma visão de que os humanos podem conquistar algo maior que nossa condição presente.. Contudo, diferentemente de muitos adeptos de religiões, os transhumanistas buscam tornar seus sonhos reais neste mundo, depositando sua confiança não em poderes sobrenaturais ou intervenção divina, mas no pensamento racional e na empiria, através do contínuo desenvolvimento científico, tecnológico, econômico e humano. Alguns dos prospectos que costumavam ser apanágio exclusivo das instituições religiosas, tais como duração de vida extremamente longa, êxtase contínuo e inteligência de caráter divino estão sendo discutidos pelos transhumanistas como hipotéticas conquistas da futura engenharia. ${ }^{11}$

${ }_{11}$ (http://transhumanism.org/index.php/WTA/faq21/82/). 
Tecnologia e ciência vêm assumir o lugar antes ocupado pela ritualística, mas permanece a retórica da transcendência, e agora, em uma perspectiva marcadamente gnóstica, é o sujeito humano que vem tomar feições divinas. Numa entidade como a curiosa "Igreja do Vírus" (Church of Vírus), a idéia de uma filosofia evolucionista e pós-humanista como nova forma de religião é explicitamente tematizada:

Se uma nova religião é planejada em torno da premissa de continuamente integrar melhores conceitos (mais precisos, mais úteis), ao mesmo tempo em que assegura a sobrevivência de seus crentes, ela poderia provavelmente alcançar a verdadeira imortalidade (http://virus.lucifer.com/about.html).

Utilizando a linguagem da teoria dos memes, do geneticista Richard Dawkins, a Igreja do Vírus prega uma religião de caráter racional, um sistema de crença baseado em idéias que "se apóiam mutuamente", como ciência, tecnologia, filosofia e religião - uma "filosofia neo-cibernética para o século XXI" (ibid.).

Mas a apropriação do discurso religioso pelas filosofias pós-humanistas na rede não se dá unicamente no plano da forma. Se para entidades como a WTA, os sentidos mais tradicionais da religiosidade e do espiritualismo devem ser superados pelas ideologias transhumanistas, para o Instituto Spiritech não existe nenhuma espécie de divórcio entre espiritualidade e tecnologia - como, aliás, o próprio nome indica (spiritual technology). Seu movimento busca manifestar não apenas a forma, mas também o próprio conteúdo de certos discursos religiosos (especialmente aqueles que se costuma classificar no âmbito do vago qualificativo de "espiritualidade New Age"). O objetivo do Instituto é promover o desenvolvimento do ser humano por meio de interfaces originais entre as novas tecnologias e dimensões metafísicas e espirituais da existência. Algumas das afirmações dos membros da entidade chegam a ser risíveis em sua ingenuidade. Carol Willis chega a afirmar que expandir habilidades intuitivas e criativas em outras dimensões. 


\begin{abstract}
Testemunhe a telepatia e intuição que ocorre no ciberespaço como cada pessoa carrega uma assinatura única de energia de luz que se origina diretamente através dos pixels de sua tela de computador e é muito claramente percebida por você como um ser espiritual (http://members.lycos.co.uk/spiritechuk)
\end{abstract}

A tecno-espiritualidade é assim encarada como via de acesso privilegiada para as experiências de uma nova humanidade, cujos corpos e mentes se encontrarão "integrados com as máquinas" em estado de perfeita harmonia. Termos como "cibermisticismo" e "ciberespíritos" acompanham, nas páginas do curioso site, a tradicional retórica do ciberespaço como reedição da Cidade de Deus, a nova Jerusalém Celestial (Cf. Wertheim, 1999). No multiverso das redes digitais estaremos todos "realizando nosso verdadeiro destino, trazendo novos significados à profecia bíblica" (http://members.lycos.co.uk/spiritechuk/background.html) ..$^{12}$

A associação entre os temas tecnológicos do pós-humanismo e uma religiosidade de tipo gnóstica ou esotérica é tão pregnante na rede que Michael Lieb dedica importante parte de seu intrigante estudo sobre a sobrevivência da narrativa de Ezequiel à análise das mitologias propaladas pela Flower of Life Research (http://www.floeweroflife.org). A organização, fundada pela curiosíssima figura de Drunvalo Melchizedek. Criada com o objetivo de promover a evolução espiritual do ser humano, a "Flor da Vida" nos apresenta em seus discursos uma fascinante combinação de sincretismo religioso (Cabala, New Age, channeling...), mitologias ufologistas e vocabulário tecnológico. Para alcançar um estágio de evolução espiritual, o indivíduo deve, por exemplo, limpar seus "circuitos elétricos". Como define Lieb, as fantasias conjuradas por Drunvalo, "evocativas do domínio das ficções massivas (pulp fiction), não se encontram a grande distância do sombrio mundo ciberespacial de William Gibson". Trata-se de uma "escatologia

\footnotetext{
$12 \mathrm{O}$ site oferece uma enorme riqueza de informações para o estudioso dos temas da tecnoespiritualidade. É uma pena, porém, que apresente inúmeros links quebrados e conexões desativadas.
} 
ciberespacial, na qual a mentalidade ciborgue de dissociação, deslocamento e mesmo anomia prevalece. Tudo é 'virtual': nada é 'real"' (1998: 73). A complexidade tipicamente gnóstica dos ensinamentos da Flower of Life esconde, porém, como em tantos outros discursos das subculturas tecnoespiritualistas, um imaginário tipicamente infantilizado, ingênuo e, em última instância, irracional. Aqui, muito propriamente, podemos evocar o célebre dito de Goya, "os sonhos da razão produzem monstros".

\section{Infantilismo e Retorno ao Paraíso Primordial}

Um dos mais interessantes paradoxos dos discursos pós-humanistas é que, não obstante seu caráter projetivo e futurístico, em última instância almejam o retorno a um passado mítico e paradisíaco. O futuro é pensado como reconquista do estado de bem-aventurança perdido pelo homem após a expulsão do Éden. Richard Coyne explica como as narrativas digitais implicam certa

\footnotetext{
inocência, um retorno a uma unidade primal, a um estado quando éramos verdadeiramente onipotentes, nossa vontade convergia com a da natureza e não havia diferenciação entre nossas demandas e o todo, o que, de acordo com alguns comentadores, é estado da primeira infância (2001: 4).
}

De fato, em muitos dos manifestos e declarações pós-humanistas é fácil detectar esse desejo de reconquista da inocência infantil. O pós-humano é a criança de uma nova era tecnológica na qual o mundo se torna um grande playground. Muitas das imagens e metáforas utilizadas nas narrativas transhumanistas possuem um sabor infantil. É o caso da alegoria com que se inicia o Manifesto do Movimento FutureCulture. Uma criança de cinco anos passeia numa paisagem idílica e bucólica, espécie de paraíso imaginário. Em suas mãos, um arame de produzir bolhas de sabão. A criança sopra diversas bolhas, que se desdobram em outras mais, coloridas, belas, complexas. Como explica o manifesto, as bolhas são uma "metáfora" das diversas subculturas 
que compõem o mundo da cibercultura (http://futurec.taylor.org/docs/bubble.txt). As bolhas voam, se combinam, se desintegram ou se transformam. Em uma bela imagem infantil, é nos oferecida uma descrição do rápido e contínuo dinamismo das novas culturas digitais. São culturas da juventude, de uma visão romântica da unidade que ainda pode ser reconquistada por meio das "novas" e "jovens" tecnologias. Não é sem razão que um texto do Instituto Spiritech destaca o papel dos infantes nesse admirável mundo novo: "nossas crianças, cujas mentes estão sendo modificadas pela constante interação com a alta tecnologia, podem ter algo a nos ensinar sobre o salto que estamos dando" (http://members.lycos.co.uk/spiritechuk/background.html).

O tema da infância e da recuperação do Paraíso primordial serve ainda para nos advertir sobre os perigos de alguns dos mitologemas pós-humanos. Como nota Tiziana Terranova, falta história e política à visão dos póshumanistas. No discurso (infantilizado) do triunfo absoluto da vontade humana tecnologizada, a "sociedade é apagada e o universo social emerge como um agregado fragmentário de indivíduos em um vazio sem restrições históricas e materiais" (2002: 275). Esse vazio é o próprio paraíso virtual dos discursos pós- e transhumanos. Seu perigo é manter nossa concepção do fenômeno tecnológico presa a uma imaginação utópica desvinculada das experiências do mundo real, com seus processos de exclusão, desigualdade econômica e poderio tecno-científico. Se o "culto da Internet", como define Breton o imaginário sobre as novas tecnologias, constitui de fato uma religiosidade “de jovens e para jovens”, seu valor supremo é a velocidade (2000: 87-88), uma velocidade que precisamente não permite o pensamento reflexivo e crítico, deixando assim o imaginário inteiramente livre para sonhar suas utopias tecno-espirituais. Mas, desprovida desse componente crítico, nossa percepção tecnológica correrá o risco de engendrar uma cultura para poucos, um novo mundo elitista e excludente, como eram as seitas gnósticas dos primeiros séculos. E esse é um sonho do qual vale a pena despertarmos. 


\section{Referências Bibliográficas}

Breton, Philippe. Le Culte de l'Internet: une Menace pour le Lien Social?. Paris: La Découverte, 2000.

Bukatman, Scout. Terminal Identity: the Virtual Subject in Post-Modern Science Fiction. Durham, Duke University Press, 1998.

Coyne, Richard. Technoromanticism: Digital Narrative, Holism, and the Romance of the Real. Cambridge: The MIT Press, 2001.

Davis, Erik. Techgnosis: Myth, Magic+ Mysticism in the Age of Information. New York: Three Rivers Press, 1998.

Dery, Mark. Escape Velocity: Cyberculture at the End of the Century. New York: Grove Press, 1996.

Ferrer, Christian. Mal de ojo: el drama de la mirada. Buenos Aires: Colihue, 1996.

Haraway, Donna. "Manifesto Ciborgue: ciencia, Tecnología e FeminismoSocialista no Final do Século XX", in Silva, Tomaz Tadeo da (org). Antropologia do Ciborgue. Belo Horizonte: Autêntica, 2000.

Le Breton, David. L'Adieu au Corps. Paris: Métailié, 1999.

Lemos, André. Cibercultura: Tecnología e Vida Social na Cultura Contemporânea. Porto Alegre: Sulina, 2002.

Lieb, Michael. Children of Ezekiel: Aliens, UFOs, the Crisis of Race and the Advent of End Time. Durham: Duke University Press, 1998.

Martins, Hermínio. Hegel, Texas - e Outros Ensaios de Teoria Social. Lisboa: Século XXI, 1996.

Noble David. The Religion of Technology: the Divinity of Man and the Spirit of Invention. London: Penguin Books, 1999.

Rüdiger, Francisco. Elementos para uma Crítica da Cibercultura. São Paulo: Hacker, 2002.

Rutsky, R. L. High Techné: Art and Technology from the Machine Aesthetic to the Posthuman. Minneapolis: University of Minnesota Press, 1999.

Sconce, Jeffrey. Haunted Media: Electronic Presence from Telegraphy to Television. Durham: Duke University Press, 2000.

Sfez, Lucien. A Saúde Perfeita: Crítica de uma Nova Utopia. São Paulo: Loyola, 1996.

Sibilia, Paula. O Homem Pós-Orgânico: Corpo, Subjetividade e Tecnologias

Digitais. Rio de Janeiro: Relume-Dumará, 2002.

Terranova, Tiziana. "Post-Human Unbounded: Artificial Evolution and HighTech Subcultures”, in Bell, David \& Kennedy, Barbara M. (orgs.). The

Cibercultures Reader. New York: Routledge, 2002.

Wertheim, Margaret. The Pearly Gates of Cyberspace: a History of Space from Dante to the Internet. New York: W. W. Norton \& Company, 1999. 


\section{Relação de sites consultados:}

- World Transhumanist Association http://www.transhumanism.org/index.php/WTA/index/

- Spiritech UK Institute - http://members.lycos.co.uk/spiritechuk/

- Extropy Institute - http://www.extropy.org

- Posthuman. Com - http://www.posthuman.com

- Church of Virus - http://virus.lucifer.com

- Flower of Life - http://www.floweroflife.com

- FutureCulture - http://www.futureculture.org

- Viridian Design - http://www.viridiandesign.org 